\title{
A Auto-referencialidade da TeOria dos Sistemas Autopoiéticos De TEUBNER COMO A SUPOSTA SUPERAÇÃO DO MITO DA NEUTRALIDADE DE KELSEN
}

\author{
THE SELF-REFERENTIALITY OF GUNTHER TEUBNER'SAUTOPOIETIC SYSTEMS \\ THEORY AS THE ALLEGED OVERCOMING OF THE MYTH OF KELSEN'S \\ NEUTRALITY
}

Artur Micael Flamínio da Silva*

\begin{abstract}
Sumário: Introdução. 1. Autopoiéses. 2. A clausura sistémica, a auto-referência e a circularidade. 3. A autoreferência e as suas várias dimensões. 4. A autonomia do Direito como sujeito autopoiético. 5. A Justiça em Teubner: uma fórmula de contingência e de transcendência 6. O relativismo axiológico de Kelsen e a Grundnorm 7. A autoreferencialidade como a suposta superação da neutralidade absoluta do sistema jurídico. Considerações Finais.
\end{abstract}

Resumo: O presente artigo tem por objecto o conceito de justiça de Gunther Teubner. Pretende-se analisar criticamente uma das teorias de maior impacto na história recente da Teoria do Direito, partindo do conceito de autoreferencialidade e fazendo a ponte com a relatividade axiológica da teoria de Hans Kelsen.

Palavras-chave: Autopoiéses. Justiça. Teoria do Direito.

Abstract: The present article deals with Gunther Teubner's concept of justice. The aim of it is to critically examine one of the theories with most impact on law, starting with the concept of self-referentiality and relate it with axiological relativity of Hans Kelsen's theory.

Keywords: Autopoiesis. Justice. Theory of Law.

\section{INTRODUÇÃO}

O presente trabalho versa sobre a teoria dos sistemas autopoiéticos de GUNTHER TEUBNER. Escolhêmo-lo, em particular, pois estamos perante uma temática que é das mais interessantes - senão a mais interessante - desta teoria sociológica do Direito.

Para o efeito, abordaremos três questões fundamentais e intimamente relacionadas:

i) Em primeiro lugar, faremos uma incursão, a título introdutório, pela teoria dos sistemas autopoiéticos em geral.

ii) Em segundo lugar, pretendemos densificar o conceito de autoreferencialidade, enquanto conceito central desta teoria. No entanto, iremos abordar a questão da Justiça em correlação com a ideia de autoreferência, nos termos propostos por TEUBNER.

iii) Por outro lado, temos o propósito de contrapor o conceito de autoreferencialidade à Grundnorm (em sentido lógico-jurídico) de HANS

iv) KELSEN, de forma a compreendermos se os descompromissos axiológicos são idênticos.

Por conseguinte, as questões fulcrais de que nos ocuparemos são as seguintes: Será que o Direito enquanto sistema autopoiético é um sistema axiologicamente neutro? A ser verdade, estamos perante uma teoria que professa uma neutralidade absoluta como KELSEN? Qual o papel da auto-referencialidade no domínio do compromisso axiológico?

\footnotetext{
* Doutorando da Faculdade de Direito da Universidade Nova
} 


\section{A AUTOPOIÉSIS}

A teoria dos sistemas autopoiéticos é inspirada no trabalho dos biólogos Francisco VAREla e Humberto Maturana plasmado na obra "De Maquinas y Seres Vivos"i em 1972.

Nesta obra, consideram que os seres vivos são unidades e, qualificando uma unidade apenas numa operação cognitiva básica de distinção, afirmam que a unidade é uma: "entity distinct from a background, characterize both unity and background with the properties with which this operation endows them, and specify their separability. A unity thus specified is a simple unity that defines trough its properties the space in which it exists and the phenomenal domain which it may generate in its interactions with other unities".

Assim, quando um sistema autopoiético é tratado como uma unidade: “(...) it exists in the space defined by its components, but if it this characterize its properties as a simple unity, and defined the space in which it exists as such a simple unity"ii .

Os seres vivos são, por isso, máquinas iii .

As relações que se geram, pela dinâmica de interacções e transformações no seio da unidade, constituem a "organização" da máquina. E as relações estabelecidas, entre os componentes da mesma, integrados num determinado hiato temporal, representam a sua "estrutura",

Note-se, porém, que segundo estes autores: "the organization of a machine (or system) does not specify the properties of the components which realize the machine as a concrete system, it only specifies the relations which these must generate to constitute the machine or system as a unity. Therefore, the organization of a machine is independent of the properties of its components which can be any, and a given machine can be realized in many different manners by many different kinds of components".

Definem, para o efeito, máquina autopoiética como: "a machine organized (defined as a unity) as a network of processes of production (transformation and destruction) of components that produces the components which: (i) trough their interactions and transformations continuously regenerate and realize the network of processes (relations) that produced them; and (ii) constitute it (the machine) as a concrete unity in the space in which they (the components) exist by specifying the topological domain of its realization as such a network"v .

Por outro lado, apontam como características destas máquinas autopoiéticas: i) a autonomia, pois estas subordinam todas as suas alterações à manutenção da sua própria organização; ii) a individualidade obtida através da imutabilidade da dessa organização no processo produtivo, mantendo-se independente do "observador"; iii) são unidades (unities) na medida em que as suas operações especificam a sua própria estrutura no processo de autoreprodução; iv) por último, estas máquinas não possuem nem "inputs" nem "outputs"vi .

Foi LUHMANN quem transpôs esta teoria para o domínio das ciências sociais, realçando que os sistemas sociais não são autopoiéticos de segundo grau desenvolvido a partir dos indivíduos humanos (cuja base reprodutiva é a vida), mas antes sistemas noéticos cuja base reprodutiva é o sentido, ou seja, composta por comunicações ${ }^{\mathrm{vii}}$.

Para este efeito, acto comunicativo é toda a interacção simbolicamente cristalizada que, ainda que de forma não voluntária, sucede a gerar e desenvolver um determinado padrão intersubjectivo de conduta ${ }^{\text {viii }}$.

Usando a auto-referencialidade para designar a produção e reprodução pelo próprio sistema dos seus elementos, no âmbito de uma sequência circular e fechada, transpõe uma inovação inspirada pela autopoiésis do domínio da biologia: "a de 
sublinhar que os sistemas autopoiéticos não são apenas sistemas auto-organizados, isto é, sistemas capazes de gerar a sua própria ordem a partir da rede interactiva dos respectivos elementos, mas também verdadeiramente sistemas auto-reprodutivos".

Ou seja, estes são "capazes de produzir as suas próprias condições originárias de produção, tornando-se desse modo independentes do respectivo meio envolvente". Assim, "a auto-referência sistémica é o mecanismo gerador, não apenas da ordem sistémica ("estrutura"), mas das próprias unidades básicas ("elementos").",ix Pelo que o sistema jurídico se tornou um subsistema social através do seu código binário próprio (legal/ilegal) ${ }^{\mathrm{x}}$, operando como centro de gravidade de uma rede circular e fechada de operações sistémicas.

Para TEuBner, o Direito "constitui um sistema autopoiético de segundo grau, autonomizando-se em face da sociedade, enquanto sistema autopoiético de primeiro grau, graças à constituição auto-referencial dos seus próprios componentes sistémicos e à articulação destes num hiperciclo" "xi .

Por outro lado, considera que o Direito enquanto sistema autopoiético se caracteriza pela comunicação e não pelas regras ou decisões jurídicas. A comunicação seria sintetizada em três aspectos: exteriorização, informação e compreensão ${ }^{\text {xii }}$.

E se é verdade que o modelo "autopoiético arranca de uma clausura operacional dos sistemas sociais que torna efectivamente impossível a participação de um sistema na autopoiésis de outro sistema"xiii, também não o é menos que a "resistência dos subsistemas sociais às tentativas de regulação externa, procedente da clausura autoreferencial própria daqueles, torna-se antes patente em dois aspectos diferentes: na indiferença à sua adequação ao meio envolvente e na imunidade às medidas regulatórias introduzidas" ${ }^{\text {xiv }}$.

Logo, é por via da autonomia dos subsistemas sociais corporizada nas relações auto-referenciais, que estes se tornam inacessíveis à intervenção jurídica directa ${ }^{\mathrm{xv}}$.

Apesar disso, convém realçar que o Direito é cognitivamente aberto, permitindo receber elementos do exterior e, por outro lado, normativamente fechado quando a sua linguagem própria define esses elementos vindos do exterior do ponto de vista interno do sistema.

Serão, pois, apenas possíveis intervenções indirectas: observação sistémica mútua e articulação pela interferência.

E essa regulação social operada pelo Direito é feita através de dois mecanismos: a informação e a interferência.

Na primeira, o Direito surge "gerando continuamente informação interna a partir do seu interior do seu próprio sistema" produzindo uma "realidade jurídica autónoma" que orienta as suas operações sem qualquer contacto real com o meio envolvente"xvi .

No outro caso, o Direito "encontra-se ligado ao respectivo meio envolvente através de mecanismos de interferência intersistémica (designadamente, as recíprocas pressões de articulação do sistema jurídico com a sua envolvente, originadas na sequência de sobreposição de eventos, estruturas e processos dentro e fora daquele sistema)"xvii.

Em termos sintéticos, a teoria dos sistemas autopoiéticos pode ser reduzida a quatro pontos essenciais:

i) Os sistemas autopoiéticos definem a sua identidade por oposição ao exterior (ambiente) e definem as regras das transacções entre o sistema e o exterior.

ii) produzem os seus próprios elementos.

iii) criam uma linguagem própria do seu ciclo de funcionamento.

iv) constroem uma nova linguagem, que comanda as transformações da primeira, de ciclo para ciclo. E é esta linguagem que permite definir o modo como o 
exterior, é reflectido internamente, ou seja qual o seu sentido dentro da lógica do sistema.

Nesta medida, o Direito também é um sistema autopoiético, por construir o seu universo de factos jurídicos, definindo o que é relevante da realidade exterior ao sistema, para a linguagem própria do mesmo. Assim, estabelece os seus próprios valores jurídicos e os seus critérios de atribuição dos valores aos factos jurídicos. E, por fim, ao definir os processos de formulação de novas regras jurídicas e da sua transformação ${ }^{\text {xiii }}$.

Estas teorias são também designadas como teorias funcionalistas do Direito, pois desempenham "uma função específica necessária à reprodução da sociedade no seu conjunto"xix , pelo que operam segundo uma lógica de diferenciação funcional. ${ }^{\mathrm{xx}} \mathrm{Ou}$ seja, é o sistema que de um modo funcional aceita ou rejeita os factos vindos do exterior (meio ambiente).

\section{A CLAUSURA SISTÉMICA, A AUTO-REFERÊNCIA E A CIRCULARIDADE}

Devemos lembrar que em plena sociedade de risco $^{x x i}$, os desafios colocados à positividade do Direito são vertiginosos e que a autopoiésis surge como uma síntese do positivismo legalista e da sociologia. A teoria do Direito do séc. XX foi caracterizada pela tensão existente entre estas duas visões antagónicas: a inspirada pela Teoria Pura do Direito do positivista legalista KELSEN e pela visão mais empírica da Sociologia do Direito, mas o debate teórico foi ganho por KELSEN e, por isso, a autopoiésis surge, como afirma FRANÇOIS EwALD, enquanto: "the daughter of Kelsen's Pure Theory"xxii.

Neste contexto, um dos atractivos desta teoria é o conceito de clausura sistémica (operational closure).

É através dele que tanto LUHMANN, como TEUBNER ultrapassam ${ }^{\text {xiii }}$ a questão da legitimidade/validade que levou KELSEN a "forjar" uma norma fundamental pressuposta $^{\text {xxiv }}$ e HART a teorizar uma norma de reconhecimento ${ }^{x x v}$.

De acordo com LUHMANN, estaremos perante um sistema enclausurado operativamente quando este para a produção das suas próprias operações, remete para o quadro operativo próprio e neste sentido se produz a si mesmo.

Nesta operação o sistema pressupõe-se a si próprio e determina, num processo de selecção e diferenciação, o que pertence ao sistema e o que não engloba o mesmo. ${ }^{\text {xvi }}$

$\mathrm{O}$ autor utiliza este conceito, em associação à sua ideia de sistema que, nas suas palavras, consiste num: "context of factually enacted operations, which have to be communicated because they are social operations, whatever defines them - and in addition to that - have to be communicated as legal communication. This means, however, that the basic distinction is not to be found in a typology of norms or values but in distinction between system and environment"xxvii.

Deste modo, considera que esta clausura sistémica consiste essencialmente numa operação de constante separação entre o que pertence ao sistema e daquilo que pertence ao exterior do sistema. Estamos, essencialmente, perante uma operação de diferenciação ao nível intra-sistémico, mas também ao nível extra-sistémico (na distinção entre o sistema e o exterior).

Mas isto não significa que estamos perante uma "clausura causal" (e consequentemente de total isolamento), isto porque a clausura operativa se separa das relações causais entre o sistema e o exterior ao definir o seu objecto ${ }^{\text {xxviii }}$.

Portanto, sendo os sistemas sociais abertos (cognitivamente) ${ }^{\text {xxix }}$ e fechados (operativamente) ao mesmo tempo, isto significa que, segundo o que acabamos de 
referir anteriormente, o conceito de auto-referencialidade se confunde com o de clausura sistémica.

TEUBNER sustenta que são idênticos porque representam "o carácter fechado, circular e recursivo da organização dos processos auto-reprodutivos de um sistema" "xxx .

Assumimos, porém, que temos muitas dúvidas relativamente ao atingir de uma auto-referencialidade "pura", pois no limite a auto-referencialidade jurídica deriva da sua autonomização do sistema que é a Sociedade ${ }^{\mathrm{xxxi}}$.

Por outro lado, afirma o autor que "o Direito determina-se a ele mesmo por autoreferência, baseando-se na sua própria positividade", para logo de seguida adiantar que o "Direito retira a sua própria validade dessa auto-referência pura, pela qual qualquer operação jurídica reenvia para o resultado de operações jurídicas". Além disso, acrescenta que "validade do Direito não pode ser importada do exterior do sistema jurídico, mas apenas a partir do seu interior"xxxii .

Ora, seguindo esta posição, o próprio Direito repousaria, ele mesmo, sobre um paradoxo. Através da sua pretensão de validade universal do binómio "legal/ilegal", não resistiria à tentação de valer por si mesmo, criar-se e regular-se autonomamente, isto é, se causa inicial externa ${ }^{\text {xxxiii }}$.

Mas basta uma pergunta para por em crise esta pretensão: Será legal a distinção "legal/ilegal"?

Como referimos, KELSEN para justificar o fundamento último do Direito usa uma presssuposta norma fundamental ou Grundnorm, TEUBNER utiliza a circularidade em conjugação com a auto-referência para ultrapassar este problema.

Assim, entende-se por circularidade o movimento circular ao nível da hierarquia das fontes, em que a fonte superior aparece legitimada pela fonte inferior, levando a que o sistema se torne auto-reflexivo, isto é, encontre dentro do próprio sistema forma de legitimação $o^{\mathrm{xxiv}}$.

Pois bem, o conceito de auto-referência "pressupõe que os pilares ou bases do funcionamento dos sistemas residem, não nas condições exógenas impostas pelo meio envolvente às quais tenham de se adaptar da melhor forma possível (como era entendido pela teoria dos sistemas abertos), mas afinal no próprio seio sistémico" ${ }^{\text {"xxv }}$.

\section{A AUTO-REFERÊNCIA E AS SUAS VÁRIAS DIMENSÕES}

TEUBNER julga que, no âmbito da qualificação das diversas dimensões do fenómeno auto-referencial, existe uma confusão terminológica na doutrina, tendo por base uma tentação de equiparar, à autopoiésis em sentido próprio, qualquer fenómeno que se assemelhe a esta característica das teorias funcionalistas.

Ora, Considera, assim, que existe uma verdadeira "confusão conceptual sem redenção", dando-lhe o nome de "galáxia auto"xxxvi.

Para tentar resolver este problema, propõe a adopção de um conceito amplo de auto-referência, de forma a abranger "todas as formas possíveis de circularidade e recursividade pelas quais uma unidade entra em relação consigo própria", permitindo que esse conceito englobasse "fenómenos tais como os de causalidade circular, feeeback, reenvio, auto-regulação, auto-catálise, assim como referência intradiscursiva, auto-observação, criação espontânea de ordem e auto-reprodução (que nada mais são do que meras manifestações particulares da auto-referência), e ainda toda a espécie de relações lógicas circulares, como tautologias, contradições, retornos infinitos e paradoxos",xxxvii. 
No entanto, este conceito amplo permitiria, distinguir, desde logo, a autoreferência nos seus distintos estádios de evolução, podendo o sistema ser autoreferencial sem ser verdadeiramente autopoiético ${ }^{\mathrm{xxxvii}}$.

Em primeiro lugar, quando nos referimos a auto-observação estamos a designar "a capacidade de um sistema influenciar as suas próprias operações para além de uma mera articulação sequencial destas"xxxix. Neste caso, em vez de proceder à repetição constante da mesma função, o sistema constrói as suas operações de modo a influenciar os futuros desenvolvimentos das suas próprias operações.

Isto significa que o sistema começa a desenvolver-se, construindo as suas operações, de modo a permitir os futuros desenvolvimentos no seio da sua acção operativa.

Por auto-descrição entende-se o carácter estrutural obtido pelas operações próprias da auto-observação, por via de uma determinada continuidade temporal e funcionando como uma plataforma de criação do sistema ${ }^{\mathrm{xl}}$.

A título de exemplo: a doutrina jurídica produz auto-descrições das operações jurídicas primárias e das respectivas estruturas, apesar de não produzir direito válido e aplicável, estrutura somente as operações da sua produção.

Com o termo auto-organização pretende-se realçar a capacidade de um determinado sistema "se estruturar espontaneamente a si mesmo: a sua ordem não é imposta pelo exterior, mas internamente através da interacção dos elementos do sistema"xli. TEUBNER, aponta a este respeito, como exemplo o sistema jurídico que utiliza as "normas secundárias" que produzem normas de conduta "primárias"xlii .

Já a auto-regulação "constitui uma variante da auto-organização, traduzindo a capacidade de um sistema não apenas de construir e estabilizar as suas próprias estruturas, mas também de as alterar de acordo com critérios próprios para essa mesma alteração"xliii . Neste caso o Direito, não desenvolve apenas "normas secundárias" para a identificação, mas também normas e processos para a alteração do Direito, e é a partir daí que este se pode considerar auto-regulado ao nível sistémico ${ }^{\text {xliv }}$.

É através dessa combinação entre auto-regulação e auto-descrição que se alcança uma identidade sistémica que é usada como critério de alteração estrutural e, que, concomitantemente, o sistema se torna auto-reflexivo.

TEUBNER exemplifica esta dimensão com as consequências práticas que a teoria e doutrina do Direito retiram perante as condições sociais vigentes por elas teorizadas ${ }^{\mathrm{xlv}}$.

Relativamente à auto-produção considera-se que um sistema é auto-produzido "quando produz os seus elementos"xlvi.

Mas esta auto-produção caracteriza-se por ser influenciada por factores endógenos e exógenos (ainda que sempre de forma mediada). E aquilo que distingue os sistemas autopoiéticos é o facto de estes se autoproduzirem "a si próprio(s) extraindo do fluxo ou sequência de eventos (que constitui assim a sua infraestrutura material energética e informacional) novas unidades que são depois articuladas selectivamente com os elementos da sua próprias estrutura"xlvii .

Porém, para o sistema atingir a autopoiésis não basta produzir os próprios elementos, mas também todos os seus componentes, como as estruturas, processos, limites, identidade e unidade do sistema. Sendo que a auto-produção "não representa senão uma condição mínima de existência de um sistema autopoiético"xlviii.

Por fim, exige-se a auto-manutenção, obtida através da conexão do primeiro ciclo de auto-produção com um segundo ciclo, que possibilite a produção cíclica garantindo as condições da sua própria produção, ou seja o hiperciclo ${ }^{\text {xlix }}$. 
É através da existência da articulação hipercíclica dos componentes sistémicos auto-gerados, enquanto elementos que se produzem entre si numa circularidade recíproca que se atinge a autopoiésis propriamente dita.

O hiperciclo garante "a estabilidade no sistema, tornando a produção dos seus componentes mais independentes em face do meio envolvente, de modo a assegurar as condições de circularidade recíproca da produção"l.

\section{A AUTONOMIA DO DIREITO COMO SUJEITO AUTOPOIÉTICO}

Por último, o sistema auto-referencial apresenta outra característica essencial. Estamos a referir-nos à sua autonomia. Dediquemos então algumas palavras à concepção Teubneriana da autonomia do Direito como sujeito autopoiético.

TEUBNER entende a sociedade como um sistema autopoiético de comunicação. Esse sistema, ao ser composto por actos comunicativos, gera continuamente novos actos de comunicação. Existe um "circuito de comunicação geral", a partir do qual se desenvolvem outros circuitos comunicativos, podendo alguns atingir um elevado grau de autonomia que lhes permite transformarem-se em sistemas autopoiéticos de segundo grau. ${ }^{\text {li }}$

E estamos ai perante "unidades de comunicação autónomas que são, por seu turno, auto-reprodutivas, gerando os seus próprios elementos, estruturam, processos e fronteiras, construindo o seu próprio meio envolvente e definindo a sua própria identidade"lii.

Assim, considera-se que "todas as vezes que uma operação, processo ou sistema se vê confrontado consigo mesmo na realidade social (seja sob a forma de produção ou observação), então emerge uma regulação de autodeterminação impossível de ser condicionada pelo exterior"liii.

Esta autonomia do Direito no sistema autopoiético representa uma realidade gradativa.

Segundo TEUBNER a autonomia jurídica abrange, "não apenas a capacidade do direito para criar os seus próprios princípios, mas também a sua capacidade de autoconstituição de acções jurídicas, a juridificação dos processos e a "invenção" de institutos jurídico-doutrinais".

Divide, para o efeito, o processo de autonomização em três fases distintas:

1- A fase do "direito socialmente difuso" - onde os elementos, estruturas, processos e limites do discurso jurídico são idênticos aos da comunicação social geral ou por esta heteronomamente determinados.

2- A fase de um "direito parcialmente autónomo" tem lugar quando o discurso jurídico começa a definir os seus próprios componentes e a usá-los operativamente.

3- Na última fase o direito torna-se autopoiético, assiste-se assim a uma articulação dos componentes do sistema entre si num hiperciclo ${ }^{\text {liv }}$.

\section{O RELATIVISMO AXIOLÓGICO DE KELSEN E A GRUNDNORM}

A positividade da Teoria kelseniana, quer-se pura $^{\text {lv }}$ e, por isso, em termos de parâmetros axiológicos descomprometida. KELSEN coloca-se na posição do cientistaobservador e que, assim, desempenha uma função meramente descritiva ${ }^{\text {lvi }}$.

É, assim, que o autor admite que "[u]uma norma jurídica não vale porque tem um determinado conteúdo, quer dizer, porque o seu conteúdo pode ser deduzido pela via de um raciocínio lógico do de uma norma fundamental pressuposta, mas porque é criada 
por uma norma fundamental pressuposta"lvii . Logo, "todo e qualquer conteúdo pode ser Direito"lviii.

Afasta, assim, por completo, uma qualquer relação axiológica da Justiça com o Direito $^{\text {lix }}$. Conclui que o Direito deve abandonar uma concepção de Justiça, pois, " [u]m direito positivo não vale pelo facto de ser justo, isto é, pelo facto da sua prescrição corresponder à norma de justiça - e vale mesmo que seja injusto" "

Recorde-se que, neste contexto, a Grundnorm representa "aquela norma que é pressuposta quando o costume através do qual a Constituição tenha surgido ou o acto constituinte (produtor da Constituição) posto conscientemente por determinados indivíduos são objectivamente interpretados como factos produtores de normas". Assim, "a norma fundamental é a instauração do facto fundamental da criação jurídica e pode, nestes termos, ser designada como <<constituição〉> em sentido lógico-jurídico (...) $)^{\text {lxi }}$. Ressalva, contudo, que “(...) não é uma norma positiva, mas uma norma pré-suposta, na medida em que a instância constituinte é considerada como a mais elevada autoridade e por isso não pode ser havida como recebendo o poder constituinte através de uma outra norma posta por uma autoridade superior""xii.

É possível, pois, afirmar que esta norma fundamental pressuposta é, como justamente adverte Luís PEREIRA COUTINHO, uma "pressuposta norma em branco de competência constituinte,"lxiii.

\section{A JUSTIÇA EM TEUBNER: UMA FÓRMULA DE CONTINGÊNCIA E DE TRANSCENDÊNCIA}

Recentemente, GUNTHER TEUBNER aborda a temática objecto do nosso trabalho, em termos concretos, e por referência ao funcionalismo jurídico.

Assim, a sua primeira afirmação é a de que "[a] sociologia do direito desconhece um qualquer conceito de Justiça"lxiv.

Rejeita, porém, a ideia Kelseniana de que o Direito se deve separar, por completo, do ideal de justiça. Assumindo, para o efeito, uma reformulação das concepções clássicas da justiça, devendo distinguir-se entre um conjunto de tipos de justiça: a justiça moral, política, económica e, em especial, a justiça jurídica ${ }^{\mathrm{lxv}}$.

A busca do paradigma de sociedade justa assume, todavia, uma enorme relevância no discurso Teubneriano, apesar de se assumir que a sociedade moderna não tem um caminho, um critério, nem um processo para aceder a essa justiça social ${ }^{\text {1xvi }}$.

TEUBNER concebe a Justiça jurídica como o processo jurídico autónomo de autodescrição que bloqueia, elimina e sabota a auto-produção das operações recursivamente rotinadas, obrigando a uma transcendência do sistema jurídico que provoque novas operações jurídicas que levem à sua reconstrução ${ }^{\text {lxvii }}$.

Expliquemos.

O autor parte de duas teorias que o ajudarão na sua análise: a autopoiésis de LUHMANN e a desconstrução de DERRIDA.

Assim, adopta um conceito de justiça que representa uma fórmula de contingência $^{\text {lxviii }}$. No entanto, esclarece que se trata de um conceito difícil e, por vezes, mal apreendido ${ }^{\text {lxix }}$. A justiça seria um valor entre outros, contudo, no Direito ela representaria uma fórmula de contingência: uma proibição de negação, uma canonização, uma indiscutibilidade, um dogma ${ }^{1 \mathrm{xx}}$.

Apesar disso, a fórmula de contingência apresenta outra dimensão: a transcendência. Esta dimensão apresenta-se como um "poder/ter de ser diferente" e ao mesmo tempo "ser dependente de algo". Logo, a fórmula opera na fronteira do Direito 
com o exterior (meio ambiente) e relaciona-se com a variabilidade histórica de Justiça e de consequente dependência do exterior ${ }^{\text {lxxi }}$.

Todavia, a busca incessante por este ideal incontestável gera um paradoxo, pois através desta procura do imutável, geram-se novas contingências.

$\mathrm{O}$ autor realça que a fórmula de contingência opera entre o sistema e o meio ambiente (exterior), apresentando-se, por um lado, como uma derivação da autoobservação do sistema - operando através de uma diferenciação funcional igual/desigual (gleich/ungleich) - e, por outro lado, como uma justiça transcendente que confere uma ligação material à consistência formal do sistema ${ }^{\text {lxxii }}$.

Logo, esta fórmula apresenta uma dimensão formal resultante da contingência da redução de complexidade pelo código operativo (legal/ilegal) e, por outro lado, tem uma dimensão material que releva da sua íntima ligação com a sociedade e o ser humano. A nosso ver, TEUBNER pretende através da auto-referencialidade enunciar uma media via entre o Direito Natural e o positivismo.

\section{A AUTO-REFERENCIALIDADE COMO A SUPOSTA SUPERAÇÃO DA NEUTRALIDADE ABSOLUTA DO SISTEMA JURÍDICO}

Com efeito, TEuBNER entende que a auto-observação permite a fixação do sistema nas suas fronteiras e, através de uma observação do exterior, transcender-se. As auto-observações do sistema jurídico operando a distinção legal/ilegal - note-se que significa de acordo com o Direito/contrário ao Direito -, acabam por confrontar-se com a dúvida da sua adequação ao exterior, efectuando a distinção justo/injusto.

Porém, o autor afasta-se de DERRIDA relativamente à transcendência do conceito de Justiça ${ }^{\text {lxxiii }}$. Estamos, pois, perante uma ideia que não corresponde a uma Justiça “divina”, à amizade ou ao perdão ${ }^{1 \times x i v}$.

Segundo Teubner, o que move a Justiça é o paradoxo que afronta o sistema jurídico: é justo utilizar a distinção legal/ilegal?

Por outro lado, julga que esta transcendência deve ser pensada apenas sem uma referência a Deus, mas que, no entanto, é sempre uma transcendência que tem de ser admitida. Esclarece que não estamos perante o jusnaturalismo, nem perante $\mathrm{o}$ positivismo. Este conceito de Justiça reconhece que ambos estão certos e paradoxalmente errados também.

A questão é que com o Direito natural partilha o impulso de buscar a Justiça fora do Direito e, por outro lado, recolhe do positivismo a negação de autoridades exteriores ao sistema, quer seja Deus, a natureza ou a razão, sendo apenas possível construir a Justiça dentro do sistema ${ }^{\text {lxxv }}$.

A Justiça é, por isso, uma força subversiva através do qual o Direito se "revolta" contra a juridicamente estabelecida rotina, estabilidade e autoridade. A Justiça seria assim apenas uma permanente "irritação" intrínseca ao Direito, pois apenas num Mundo em que existisse um Deus de "carne e osso" é que nos seria possível alcançar uma Justiça libertadora ${ }^{\mathrm{lxxvi}}$.

Assim, a busca pela Justiça resumir-se-ia a uma paradoxal e viciante destruição e uma consequente e constante criação auto-referencial do próprio Direito ${ }^{\text {lxxvii }}$.

Pelo exposto, o parâmetro axiológico desta teoria é correlativo à sua própria auto-referencialidade. É através do comportamento auto-referencial do sistema jurídico, operando com a distinção legal/ilegal que este desenvolve o seu próprio parâmetro valorativo.

A auto-observação sistemática permite que as "irritações", a que o sistema está submetido, por força da constante interacção com o exterior, sejam apreendidas de 
forma a serem reconstituídas pelo sistema, introduzindo assim elementos materiais. É isto que se pode retirar da teorização feita por TEUBNER.

Porém, chega o momento em que pretendemos analisar algumas das nossas inquietações, embora sempre num paralelo com a neutralidade patente no sistema propugnado por KELSEN.

A primeira questão que nos invade o espírito é a seguinte: será o Direito completamente imune às racionalidades dos outros subsistemas sociais sendo, consequentemente, possível isolar os diferentes tipos de justiça da denominada "justiça jurídica"?

Consideramos que a teorização efectuada por TEUBNER é bastante atractiva quando admite a existência de vários tipos de justiça. Efectivamente, o autor detecta um problema relevante ${ }^{\text {lxxviii }}$ o da necessidade de separar as racionalidades de outros subsistemas sociais do domínio do jurídico.

As nossas objecções reportam-se apenas à possibilidade de ser posto em prática. Duvidamos, por isso, que seja possível retirar o discurso comunicativo jurídico e, consequentemente, purificá-lo, das justiças dos outros sistemas sociais. No limite, mesmo quando os subsistemas sociais estejam a actuar em conjunto, será idílico pensar que nunca se terá que sacrificar a racionalidade de um em relação ao outro ${ }^{\text {lxxix }}$.

Por outro lado, temos dúvidas acerca da existência de um qualquer sistema jurídico sem ser axiologicamente comprometido.

Expliquemos: KELSEN ancora o parâmetro valorativo na sua Grundnorm, fazendo o seguinte raciocínio: "se a primeira constituição histórica e as normas jurídicas emitidas sobre esse fundamento forem consideradas como juridicamente obrigatórias, então deverá ser pressuposta uma norma determinando que uma pessoa deve conduzirse em conformidade com a primeira constituição histórica. Essa norma é a norma fundamental de uma ordem jurídica nacional. Como podemos falar de uma ordem juridicamente obrigatória apenas se pressupusermos essa norma (que não é uma norma do Direito positivo), ela pode ser chamada de norma hipotética. Essa norma fundamental é a base de todos os juízos jurídicos de valor possíveis na estrutura da ordem jurídica de um Estado dado" ${ }^{\text {xxx }}$.

TEUBNER utiliza a auto-referencialidade para sustentar a sua teoria e os problemas de fundamentação que se encontravam em KELSEN. Note-se, porém, que ao atribuir à auto-referencialidade significado axiológico admite que o sistema jurídico tenha um qualquer conteúdo. Assim, o preço da neutralidade intra-sistemática é a possibilidade de compromisso com um qualquer parâmetro valorativo.

Como bem reconhece Luís PEREIRA COUTINHO, isto porque uma funcionalidade do sistema estará sempre ancorada num valor, numa Grundnorm, pelo que o critério é a adequação funcional e não a qualidade intrínseca, como pretende este autor ${ }^{\text {lxxxi }}$.

São, por isso, certeiras as afirmações de PINTO BRONZE (ainda que por referência a LUHMANN) quando afirma que "isto não é a justeza realizada de um modo metodonomologicamente adequado que legitima materialmente a decisão, mas que é a sua legitimidade formal no âmbito do sub-sistema do direito funcionalmente compreendido que a fundamenta", de onde se pode concluir que se "traduz, no mínimo, num arbítrio semântico"lxxxii.

Com efeito, concordamos com OLIVEIRA DE ASCENSÃo quando afirma que "[f]lagrantemente, não é possível admitir que sistemas totalitários recentes são bons se actuarem dentro de regras formais", por isso, "[a] análise do conteúdo é um risco a que não pode fugir a condição humana"lxxxiii .

Eventualmente, poderíamos concordar com a ideia de transcendência de TEUBNER, embora com limites. Julgamos que, como justamente adverte Luís PEREIRA 
CoutinHo, uma qualquer tentativa de "purificar" a compreensão do Direito permite "o comprometimento do seu "objecto" com um qualquer princípio de auto-definição excludente ou diferenciador, mais ou menos evidenciado" "lxxxiv .

Neste sentido, acompanhamos BAPTISTA MACHADO quando afirma que "o nosso conhecimento do Justo seria pelo menos capaz de alcançar 'verdades parcelares' ou reverberações da ideia de Justiça refractadas pela situação histórica, pelo que, uma vez alcançadas ou 'consciencializadas' tais parcelas da verdade, elas representariam como que etapas vencidas na evolução da humanidade", contudo, "tais verdades ou princípios nunca mais poderiam vir a ser de todo olvidados ou obliterados - porque isso representaria um retrocesso na evolução do homem""lxxxv.

Caso contrário, segundo esta teoria poderia ser possível sustentar um Direito vinculado a uma concepção axiológica totalitária e, mesmo assim, haveria que ser considerado como um Direito justo.

Julgamos que conceber a transcendência, tal como TEUBNER o faz, é materialmente idêntico ao (des)compromisso axiológico de KELSEN. Apesar de TEUBNER se afastar liminarmente desta ideia. Ainda assim, inexiste um mecanismo na sua teoria, que demonstre que a axiologia transcendente influenciadora do subsistema social jurídico não seja qualquer uma. No entanto, reconhecemos nesta demarcação de TEUBNER perante KELSEN uma tentativa de "fugir" a este relativismo axiológico.

A sua concepção de Justiça revela, porém, um avanço na teoria dos sistemas autopoiéticos: a de admitir que a validade do Direito não se resume a uma validade formal. Logo, ao admitir-se que a materialidade tem uma importante função na forma que o sistema jurídico assume, é um notável avanço em relação a LUHMANN.

\section{CONSIDERAÇÕES FINAIS}

I - O problema central que ao longo do nosso trabalho nos ocupou, foi a questão da concepção Teubneriana da auto-referencialidade como a superação do abandono da ideia de Justiça de KELSEN.

Assim, Teubner garante que a sua construção teórica se compromete com elementos materiais que são recepcionados formalmente pelo subsistema social que é o Direito. O que é fruto das permanentes "irritações" vindas do exterior ao subsistema Direito.

III - Porém, a auto-referencialidade como construção tautológica e neutral do sistema, representa, na sua essência, uma mera construção formal. Consideramos que reportar significado axiológico à auto-referencialidade sistemática tem o perigo de poder albergar qualquer tipo de valor intrínseco no Direito.

IV - Neste contexto, apesar de apontarmos diferenças enormes ao nível formal do sistema de KELSEN em relação à construção de TEUBNER, reconhecemos que em termos de possibilidade de compromisso revelam as mesmas fragilidades. Ou seja, ambas as teorias revelam um relativismo axiológico relativamente à sua consistência material.

V - Reconhecemos, no entanto, algumas potencialidades nesta nova construção, principalmente por se tratar de um avanço importante em relação a LUHMANN, admitindo-se que o um sistema auto-referencial seja comprometido com uma metanorma que determine directamente o conteúdo das bases formais que sustentam o sistema. 


\section{REFERÊNCIAS}

AMADO, J. A. Garcia. La Société et le Droit Chez Luhmann. Niklas Luhmann observateur du droit, (org) André-Jean Arnaud et Pierre Guibentif, Paris, LGDJ, 1993

ANTUNES, José Engrácia. Prefácio a Gunther Teubner. O Direito Como Sujeito Autopoiético. Lisboa Fundação Calouste Gulbenkian, 1993

ASCENSÃO, José de Oliveira. O Direito - Introdução e Teoria Geral. 13 ${ }^{\text {a }}$ Edição, Coimbra, Almedina, 2005

BECK, Ulrich; Giddens, Anthony; Lash, Scott. Modernização Reflexiva: Política, Tradição e Estética na Ordem Social Moderna, Oeiras, Celta, 2000.

BECK, Ulrich. World Risk Society, London, Polity Press, 2000.

BOBBIO, Norberto. Il positivism giuridico. Turim, Giappichelli Editore, 1996.

BRONZE. José Pinto. A Metodonomologia entre a semelhança e a diferença (Reflexão Problematizante dos Pólos da Radical Matriz Analógica do Discurso Jurídico). Coimbra Editora, Coimbra, 1994.

DERRIDA, Jacques Gesetzskraft. Der «mystische Grund der Autorität. Frankfurt, Suhrkamp, 1991.

DREIER, Horst. Rechtslehre, Staatssoziologie und Demokratietheorie bei Hans Kelsen. $2^{\text {a }}$ Edição, Baden-Baden, Nomos, 1990.

EWALD, Françoais. The Law of the Law, Gunther Teubner (ed.), Autopoiétic Law: A New Approach to Law and Society, Berlim, Walter de Gruyter.

GUIBENTIF, Pierre. O direito na obra de Niklas Luhmann. Etapas de uma evolução teórica. José Manuel Santos (org.) O Pensamento de Niklas Luhmann. Covilhã, 2005.

HART, Herbert L.A. O Conceito de Direito. Lisboa, Fundação Calouste Gulbenkian, 1996.

HESPANHA, António Manuel. O Caleidoscópio do Direito. O direito e a Justiça nos Dias e no Mundo de Hoje. $2^{\text {a }}$ Edição, Coimbra, Almedina, 2009.

Panorama Histórico da Cultura Jurídica Europeia. Mem Martins, Europa América, 1997.

KELSEN, Hans. O que é a Justiça?, $2^{\text {a }}$ Edição, tradução de Luís Carlos Borges, São Paulo, Martins Fortes, 1998

Teoria Pura do Direito. $7^{\circ}$ edição da tradução da $2^{a}$ edição de 1960, Coimbra, Almedina, 2008

LUHMANN, Niklas. EI Derecho de la Sociedad. Cidade do México, Herder, 2005 
Risk: a sociological theory, New York, De Gruyter, 1993

Operational Closure and Structural Coupling: the Differentiation of the Legal system", Cardozo Law Review, 13, 1992.

MACHADO, João Baptista. Introdução ao Direito e ao Discurso Legitimador. $17^{\text {a }}$ reimpressão, Coimbra, Almedina, 2008.

MATURANA, Humberto; VARELA, Francisco. Autopoiesis and Cognition - The Realization of the Living. Dordrecht, D. Reide, 1980.

TEUBNER, Gunther. Altera Pars Audiatur: Das Recht in der Kollision anderer Universalitätsansprüche. Archiv für Rechts- und Sozialphilosophie, nº 65, 1996

Autopoiésis in Law and Society: A rejoiner to Blankenburg. Law and Society Review, Volume 18 n 2

Dreiers Luhmann, Robert Alexy (coord.), Integratives Verstehen: Zur Rechtsphilosophie Ralf Dreiers, Tübingen, Mohr Siebeck, 2005, p. 201

Ein Konstitutioneller Moment? Die Logik des hit the bottom, Klaus Günther e Stefan Kadelbach (coord.), Recht ohne Staat, 2010

Selbstsubversive Gerechtigkeit: Kontingenz - oder Transzendenzformel des Rechst?", Zeitschriftt für Rechtssoziologie, nº 1 de 2003

"Die Episteme des Rechts - zu Erkentnisstheoretischen Grundlagen des reflexiven Rechts", Wachsende Staatsaufgaben - sinkende Steuerungsfähigkeit des Rechts, Baden-Baden, Nomos, 1990

Hyperzyklus in Recht und Organisation - zum Verhältnis von Selbstbeobachtung, Selbstkonstituition und Autopoiese, Hans Haferkamp und Michael Schmid (Ed.), Sinn, Kommunikation und soziale Differenzierung: Beiträge zu Luhmanns Theorie sozialer Systeme, Frankfurt, Suhrkamp, 1987

1993

O Direito como Sujeito Autopoiético,Lisboa, Fundação Calouste Gulbenkian,

\footnotetext{
${ }^{\text {i } E s t a ~ e ́ ~ a ~ o b r a ~ o r i g i n a l, ~ m a s ~ a o ~ l o n g o ~ d a ~ n o s s a ~ e x p o s i c ̧ a ̃ o ~ i r e m o s ~ u s a r ~ a ~ t r a d u c ̧ a ̃ o ~ i n g l e s a ~ d e s t a ~ o b r a . ~}$

${ }^{i i}$ Humberto MATURANA e FrANCISCO VARELA, Autopoiesis and Cognition - The Realization of the Living, Dordrecht, D. Reide, 1980, XIX.

iii Sendo uma máquina autopoiética: "a machine organized (defined as a unity) as a network of processes of production, transformation and destruction of components that produces the components which: i) trough their interactions and transformations regenerate and realize the network of processes (relations) that produced them; and (ii) constitute it as a concrete unity in the space in which they exist by specifying the topological domain of its realization as such a network. HUMBERTO MATURANA e FRANCISCO VARELA, como na nota 2, p. 135 e ainda mais especificamente à afirmação de que os seres vivos são máquinas v. p. 78.

${ }^{\text {iv }}$ HUMBERTO MATURANA e FRANCISCO VARELA, como na nota 2, p.77.

${ }^{v}$ HUMBERTO MATURANA e FRANCISCO VARELA, como na nota 2, pp.78 e 79.

${ }^{\text {vi }}$ HUMBERTO MATURANA e FRANCISCO VARELA, como na nota 2, pp. 80 e 81.
} 
vii Law as Social System, New York, Oxford University Press, 2004, pp. 73 e ss, Sobre o significado do conceito de "sentido", cfr. NikLas LuHMANN, Social Systems, Standford, Standford University Press, 1995 , pp. 59 e ss.

viii José Engrácia Antunes, Prefácio a GunTHER Teubner, O Direito Como Sujeito Autopoiético, Lisboa Fundação Calouste Gulbenkian, 1993, XI e XII.

ix José ENGRÁCIA ANTUNES, como na nota 7, XI.

${ }^{\mathrm{x}} \mathrm{E}$ é esta a linguagem do subsistema social Direito. Mas existem outros subsistemas que LUHMANN identifica tais como: a política, a religião, a arte, o sistema educativo e o sistema de tratamento de doenças. A título de exemplo, o código binário da economia seria o ter/não ter, o da ciência verdadeiro/falso e o da arte o conseguido/não conseguido. Neste sentido, PIERRE GUIBENTIF, O direito na obra de Niklas Luhmann. Etapas de uma evolução teórica, José Manuel Santos (org.) O Pensamento de Niklas Luhmann, Covilhã, 2005, p. 228.

${ }^{x i}$ O Direito como Sujeito Autopoiético,Lisboa, Fundação Calouste Gulbenkian,1993, p.53.

xii GUNTHER TEUBNER, "Die Episteme des Rechts - zu Erkentnisstheoretischen Grundlagen des reflexiven Rechts", Wachsende Staatsaufgaben - sinkende Steuerungsfähigkeit des Rechts, Baden-Baden, Nomos, 1990, p.126.

xiii GUNTHER TEUBNER, como na nota 12, p. 150.

${ }^{x i v}$ GUNTHER TEUBNER, como na nota 12, p. 154.

${ }^{\mathrm{xv}}$ GUNTHER TEUBNER, como na nota 12, p. 155.

xvi GUNTHER TEUBNER, como na nota 12, p. 130.

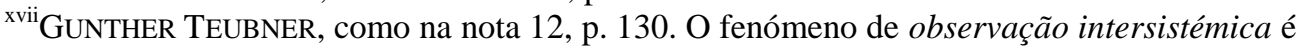
representando por uma das dimensões da auto-referencialidade, ou seja, a auto-observação. Os sistemas nunca podem ser influenciados directamente, e sendo assim, um sistema apenas pode "irritar", "comprimir" outro, provocando neste reacções internas, mas isto tudo segundo a sua lógica interna, que responderá a estas mesmas "provocações".

Apontemos um exemplo: se o legislador impuser um congelamento dos preços na economia, normalmente, este é perspectivado como um caso evidente de intervenção jurídica directa no sistema económico.

Porém, da perspectiva autopoiética representa um acto de observação, em que o Direito observa a economia através de um comando jurídico em matéria de controlo de preços.

Pelo que através do mecanismo normativo de controlo de preços, se limita meramente a observar as suas próprias operações e a imaginar o funcionamento do sistema económico deste ou daquele modo. Também do ponto de vista do sistema económico, não se importa informação externa, resumindo-se a meras observações internas no sentido de distinções e indicações intrínsecas ao sistema económico. É assim, pois, quando as normas jurídicas são consideras no cálculo económico, não são tidas em conta da sua validade normativa, mas na qualidade de itens do quadro da análise "custo-benefício". Ora, neste caso, pretende-se analisar se é economicamente racional fazer depender a observância das normas jurídicas da severidade sancionatória e da verosimilhança da sua efectiva aplicação estadual.

Logo, o Direito "inventa uma imagem da economia, formulando as respectivas normas com referência a tal imagem. A economia "inventa" uma imagem do Direito, processando os actos de pagamento também com referência a esta". Exemplo indicado por GUNTHER TEUBNER, como na nota 12, pp.155 e ss e, em especial, p. 160.

Por outro lado, Teubner refere-se à interferência intersistémica, ou seja, à interferência de sistemas autopoiéticos homogéneos, nascidos ou resultantes do processo interno de diferenciação de um sistema autopoiético mais abrangente.

Deste modo, sustenta que é esta que possibilita o contacto directo, ao nível da linguagem, recíproco entre sistemas sociais, para além da mera observação. Pelo que os sistemas sociais apenas podem comunicar "sobre" e jamais "com" a natureza e o homem. O mecanismo de interferência é uma ponte entre os sistemas sociais, graças ao qual estes ultrapassam não só os horizontes de mera auto-observação, como se articulam reciprocamente num mesmo e comum evento comunicativo. Cfr., GUNTHER TEUBNER, como na nota 12 , p.162 e, em especial, p. 173.

xviii Num sentido parecido e de um modo sintético, ANTÓNio MANUEl HeSPANHA, $O$ Caleidoscópio do Direito. O direito e a Justiça nos Dias e no Mundo de Hoje, 2a Edição, Coimbra, Almedina, 2009, pp. 209 e ss., António Manuel HeSPANHA, Panorama Histórico da Cultura Jurídica Europeia, Mem Martins, Europa América, 1997, pp. 259 e ss.

${ }^{x i x}$ PIERRE GUIBENTIF, como na nota 10, p. 204.

${ }^{\mathrm{xx}}$ Para LuHMANN, como na nota 8, pp. 142-143, a função do direito: "deals with expectations that are directed at society and not at individuals. It deals with the possibility of communicating expectations and 
having accepted in communication. "Expectation", then, does not refer to an actual state of consciousness of a given individual human being but to the temporal aspect of the meaning of communications".

${ }^{x x i}$ Por sociedade de risco entendemos o conceito que designa "uma fase de desenvolvimento da sociedade moderna na qual os riscos sociais, políticos, económicos e individuais tendem, cada vez mais, a escapar às instituições de monotorização e protecção da sociedade industrial”, ULRICH BECK, ANTHONY GIDDENS, SCOTT LASH, Modernização Reflexiva: Política, Tradição e Estética na Ordem Social Moderna, Oeiras, Celta, 2000, p. 5. Porém, a palavra Risco é considerada por ULRICH BECK numa acepção diferente da comummente conhecida: "[r]isks presume industrial, that is, techno-economic, decisions and considerations of utility. They differ from "war damage" by their "natural birth", or more precisely, their "peaceful origin" in the centres of rationality and prosperity with the blessings of the guarantors of law and order", isto porque "they are not based on decisions, or, more specifically, decisions that focus on techno-economic advantages and opportunities and accept hazards as simply the dark side of progress", cfr., a sua obra de referência, World Risk Society, London, Polity Press, 2000, p. 50. Para uma leitura mais atenta da noção de risco do ponto de vista sociológico, cfr. NIKLAS LUHMANN, Risk: a sociological theory, New York, De Gruyter, 1993, especialmente pp. 73 e ss.

${ }^{x i i}$ Neste sentido, The Law of the Law, Gunther Teubner (ed.), Autopoiétic Law: A New Approach to Law and Society, Berlim, Walter de Gruyter, p. 39. Para uma visão panorâmica sobre o positivismo jurídico, cfr., NORBERTO BOBBIO, Il positivism giuridico, Turim, Giappichelli Editore, 1996, pp. 129 e ss.

xxiii Ainda que seja em conjugação com a auto-referencialidade do Direito e principalmente da ideia de circularidade.

${ }^{\text {xxiv }}$ A Grundnorm constitui a pedra basilar do sistema erigido por KELSEN e, ao pressupô-la, consegue fundamentar o seu sistema. Sobre a norma fundamental em KELSEN cfr. HANS KELSEN, Teoria Pura do Direito, $7^{\circ}$ edição da tradução da $2^{a}$ edição de 1960, Coimbra, Almedina, 2008, pp. 224 e ss.

${ }^{\mathrm{xxv}}$ A este respeito v. HeRbERT L.A. HART, O Conceito de Direito, Lisboa, Fundação Calouste Gulbenkian, 1996, p. 111 e ss.

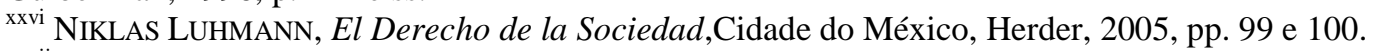

${ }^{x x v i i}$ NIKLAS LUHMANN, como na nota 8, p. 78.

xxviii Neste sentido, NIKLAS LUHMANN, como na nota 8, p. 80. E a nosso ver, a este respeito, também não podemos esquecer que estamos perante sistemas cognitivamente abertos.

xxix Sendo que o sistema comunica: "by splitting reality trough higly artificial distinction between utterance and information, both taken as contingent events within an ongoing process that recursively uses results of previous steps and anticipates further ones", V. NIKLAS LUHMANN," Operational Closure and Structural Coupling: the Differentiation of the Legal system", Cardozo Law Review, 13, 1992, p. 1424.

${ }^{\mathrm{xxx}}$ Como na nota 12 , p. 33.

${ }^{\text {xxxi }}$ Considerando que a auto-referencialidade pura não existe, Cfr. J. A. GARCIA AMADO, La Société et le Droit Chez Luhmann, Niklas Luhmann observateur du droit, (org) André-Jean Arnaud et Pierre Guibentif, Paris, LGDJ, 1993, p. 117.

xxxii Como na nota 12 , p. 2.

xxxiii Como na nota 12 , passim.

xxxiv Como na nota 12 , pp. 7 e ss.

${ }^{x x x v}$ Como na nota 12 , p. 32

xxxvi Crítica a definição de VARELA, no que respeita à equiparação da autonomia à clausura autoreferencial, assim como os conceitos de auto-produção, auto-manutenção e auto-referencialidade de RoTH. Por fim, julga discutível a distinção feita por Luhmann ao nível da estrutura e dos elementos do sistema, tal como a confusão entre auto-referência, reflexividade e reflexão. Para mais desenvolvimentos, Cfr. GUNTHER TEUBNER, Hyperzyklus in Recht und Organisation - zum Verhältnis von Selbstbeobachtung, Selbstkonstituition und Autopoiese, HANS HAFERKAMP und MICHAEL SCHMID (Ed.), Sinn, Kommunikation und soziale Differenzierung: Beiträge zu Luhmanns Theorie sozialer Systeme, Frankfurt, Suhrkamp, 1987. pp. 94-96, disponível em (http://www.jura.unifrankfurt.de/ifawz1/teubner/dokumente/Hyperzyklus.pdf).

xxxvii Como na nota 12, p. 38 .

xxxviii Como na nota 12, pp. 38 e 39.

${ }^{\text {xxxix }}$ GUNTHER TEUBNER, como na nota 12, pp. 40 e 41.

${ }^{x l}$ GUNTHER TEUBNER como na nota 12, p. 41.

xli GUNTHER TEUBNER, como na nota 12, p. 42.

xlii De modo muito semelhante ao que teoriza HART, ainda que em contexto e âmbito diferente. Cfr.

HERBERT L. A. HART, como na nota 26, pp. 89 e ss.

xliii Como na nota 12, p. 42. 
xliv GUNTHER TEUBNER, como na nota 12, p. 43.

${ }^{x l v}$ Como na nota 12, p. 43.

xlvi GUNTHER TEUBNER,como na nota 12, p. 43.

xlvii GUNTHER TEUBNER, como na nota 12, p. 46.

xlviii GUNTHER TEUBNER, como na nota 12, p 47.

xlix GUNTHER TEUBNE, como na nota 12, pp. 48 e 49.

${ }^{1}$ GUNTHER TEUBNER, como na nota 12, p. 69.

${ }^{\text {li }}$ Como na nota 12 , p. 139.

lii Como na nota 12, p. 139.

liii Como na nota 12, p. 72.

${ }^{\text {liv }}$ GUNTHER TEUBNER, como na nota 12, p. 77. Numa fórmula sintética: Para TeUBNER o Direito é autónomo quando é auto-referencial e autopoiéticamente organizado, "Autopoiésis in Law and Society: A rejoiner to Blankenburg", Law and Society Review, Volume 18, n 2, p. 87.

Iv Lembramos que o que KELSEN pretende saber é: "o que é o Direito?" rejeita, no entanto "a questão de saber como deve ser o Direito, ou como deve ele ser feito". Acrescentando que a sua teoria é "pura", pois, (...) "ela se propõe garantir um conhecimento apenas dirigido ao Direito e excluir deste conhecimento tudo quanto não pertença ao seu objecto, tudo quanto se não possa, rigorosamente, determinar como Direito", isto é "ela pretende libertar a ciência jurídica de todos os elementos que lhe são estranhos". Cfr. HANS KELSEN, como na nota 24, p. 1.

lvi Ressalve-se que a nossa análise terá por objecto, em primeira linha, a norma fundamental pressuposta. Para uma análise crítica da Grundnorm de Kelsen, cfr., HORST DREIER, Rechtslehre, Staatssoziologie und Demokratietheorie bei Hans Kelsen, 2ª Edição, Baden-Baden, Nomos, 1990, pp. 42 e ss.

${ }^{\text {lvii }}$ Como na nota 24, p. 220. Porém, este descompromisso revela um paradoxo: a do compromisso através dessa mesma norma. Como afirma LUís PEREIRA COUTINHO "[KELSEN] ao atribuir à norma fundamental um carácter prescritivo, (...) já não a configura como pressuposição epistemológica do "cientista" (observador auto-configurado como descomprometido), isto é, como "condição lógico-transcendental" do conhecimento do Direito (do conhecimento de normas válidas, não havendo normas jurídicas que não sejam normas válidas)". Cfr., A Autoridade Moral da Constituição - da Fundamentação da Validade do Direito Constitucional, Coimbra, Coimbra Editora, 2009, p. 509.

lviii Idem.

lix $\mathrm{O}$ que se nota também nesta passagem: "[u]ma teoria jurídica positivista não reconhece o fundamento de validade de uma ordem jurídica positiva em qualquer das muitas normas de justiça - pois não pode dar a qualquer delas preferência sobre as demais - mas, como já se mostrou, numa norma fundamental hipotética (isto é, pressuposta pelo pensamento jurídico) por força da qual nos devemos conduzir e por força da qual devemos tratar os homens tal como for conforme a uma primeira constituição histórica, global eficaz, sem importar a questão de saber se a ordem jurídica erigida em conformidade com esta constituição corresponde ou não a qualquer norma de justiça". Cfr. A Justiça e o Direito Natural, Coimbra, Almedina, 2001, pp. 101 e 102.

${ }^{1 x}$ Isto não invalida, porém, que admita que a ordem jurídica positiva possa ser determinada por referência a uma qualquer norma de justiça. Como se nota nesta passagem: "Ela [a teoria pura] não nega que a elaboração de uma ordem jurídica positiva possa ser determinada - e, em regra, é-o de facto - pela representação de qualquer das muitas normas de justiça. Especialmente, não nega que toda a ordem jurídica positiva (...) pode ser apreciada ou valorada, segundo uma destas normas de justiça, como justa ou injusta". Contudo, ressalva que "uma teoria do direito positivo, nada tem a ver com uma apreciação ou valoração do seu objecto". Cfr., como na nota 59, p. 101.

${ }^{1 \times i}$ V., como na nota 59, p. 221.

lxii Idem.

Ixiii Assim, como na nota 56, pp. 498 e ss., confluindo no sentido exposto.

${ }^{\text {lxiv }} \mathrm{O}$ seu ponto de partida, consiste precisamente em saber se uma teoria sociológica do Direito, apresenta um contributo fiável para um conceito de justiça.

${ }^{\mathrm{Ixv}}$ Como se reflecte, na seguinte passagem: "Eine soziologische Sicht wird also für die Moderne ein Paradigm Lost konstatieren: Gerechtigkeit als das Ideal einer guten Gesellschaft. Doch bedeutet das nicht, dass das Recht, wie Hans Kelsen vorgeschlagen hat, die Idee der Gerechtigkeit vollends aufgeben müsste. Vielmehr muss man die alte Idee unter neuen Bedingungen reformulieren und sorgfältig zwischen unterschiedlichen Monokontexturen der Gerechtigkeit differenzieren, zwischen moralischer Gerechtigkeit, politischer Gerechtigkeit, wirtschaftlicher Gerechtigkeit - und besonders juridischer Gerechtigkeit", Cfr., GUNTHER TEUBNER, "Selbstsubversive Gerechtigkeit: Kontingenz - oder Transzendenzformel des Rechst?", Zeitschriftt für Rechtssoziologie, ${ }^{\circ} 1$ de 2003, p. 13.

${ }^{\text {Ixvi }}$ V. como na nota 65 , p. 13 . 
${ }^{1 x v i i}$ Cfr, como na nota 65, p. 22, afirmando que "Juridische Gerechtigkeit ist als die Reaktion des Rechts auf sein eigenes Versagen zu verstehen", acrescentando que transpondo para uma fórmula podia ser qualificado como "ein eigensinniger Prozess der Selbstbescreibung im Recht, der die ungest]orte Selbstreproduktion des Rechtssystems, die routinisierte Rekusrsivität der Rechtsoperationen, unterbricht, blockier sabotiert, unterminiert, der damir das Recht zu seiner Selbstranszendierung über jeden Sinn hinaus zwingt, der sich aber sogleicht wieder unter den Fortsetzungszwang, weitere Rechtsoperationen zu produzieren, setzt und sich dadurch selbst sabotiert (...)".

Ixviii TEUBNER já tinha, anteriormente, demonstrado a sua simpatia para com a concepção de DREIER que encara LUHMANN como uma espécie de neo-jusnaturalista. Afirmou, por isso, que "[k]ontingenz heisst nicht nur historische Variabilität, sondern heisst zugleich Abhängigkeit, hier also: die Abhängigkeit des Rechts von der geselschaftlichen Umwelt. Damit kommen materielle Kriterien ins Spiel. Eine alternative Interpretation würde gegenüber dem Gesichtspunkt der inneren Konsistenz den Gesichtspunkt der Gesellschaftsadäquität im sismtemtheoretischen Begriff de Gerechtigkeit heraustellen", "Dreiers Luhmann", ROBERT ALEXY (coord.), Integratives Verstehen: Zur Rechtsphilosophie Ralf Dreiers, Tübingen, Mohr Siebeck, 2005, p. 201.

${ }^{\text {Ixix }}$ Recorde-se que a concepção de justiça de LUHMANN se reporta a uma fórmula de contingência que se traduz numa dinâmica própria do subsistema, pelo que "the system itself has to define justice in such a way that makes it clear that justice must prevail and that the system identifies with it as an idea, principle, or value", sendo definida como "adequate complexity of consistent decision-making", como na nota 8 , pp. 214 e 219.

${ }_{\mathrm{lxx}}$ Teubner, a este respeito, afirma que "[j]uridische Gerechtigkeit wird als die zentrale, die eine unbestreitbare Orientierungsformel in Anspruch genommen und kann zu keinem inner- oder ausserechtlichen Prinzip in Konkurrenz treten. Als Kontingenzformel des Rechts hat Gerechtigkeit im Recht einen ähnlichen Status wie ihn andere Kontingenzformeln auf anderen Gebieten ebenfalls haben: Legitimität in der Politik, Gott in der Religion, Gütterknappheit in der ökonomie, Bildung in der Pädagogik, Limitionalität in der Wissenschaft. Kontingenzformel heist: Negationsverbot, Kanonisierung, Unbestreitbarkeit. Und ihre Dynamik enthüllt ein Paradoz. Die notwendige Suche nach dem unbestreibaren erzeut, wenn sie als Suche beobachtet warden kann, immer wieder neue Kontingenzen. Notwendige Kontingenz - kontingente Notwendigkeit”, como na nota 65, p. 16.

${ }^{\text {Ixxi }}$ Como na nota 65, p. 16.

Ixxii Cfr., como na nota 65, p. 17, "[d]ie Intention der Gerechtigkeit richtet sich nicht auf die Maximierung dogmatischer Konsistenz, sondern darauf, auf äusserst divergente Anforderungen von aussen sensibel zu antworten und dabei möglichst höhe Konsistenz anzustreben. Die Kontingenformel zielt nicht auf eine dem Recht imanente, sondern eine das Recht transzendierende Gerechtigskeit. Interne Konsistenz plus Responsivität gegenüber ökologischen Anforderungen - dies ist die doppel formel juridische Gerechtigkeit".

Ixxiii Como na nota 65, p. 26

${ }^{\text {Ixxiv }}$ Segundo DERRIDA, a ideia de justiça reconduz-se a uma justiça infinita "weil sie sich nicht reduzieren, auf was zurückzuführen lässt, irreduktibel ist sie, weil sie dem Anderen gebührt, dem Anderen sich verdankt; dem anderen verdankt sie sich, gebührt sie vor jedem Vertragabschluss, da sie vom Anderen aus, von anderen her gekommen, da sie das Kommen des Anderen ist, dises immer anderen Besonderen". Por outro lado, reconhece que a Desconstrução vive deste tipo de justiça, pelo que "wegen dieser Gerechtigkeit ist sie wahnsinnig", acrescentando que "[d]iese Gerechtigkeit, die kein Recht ist, ist die Bewegung der Deskonstruktion: sie ist im Recht oder in der Geschichte des Rechts am Werk, in der politischen Geschichte und in der Geschichte überhaupt, bevor sie sich jener Diskurs präsentiert (...)", Gesetzskraft - Der «mystische Grund der Autorität», Frankfurt, Suhrkamp, 1991, pp. 51 e ss.

${ }^{1 \times x v}$ V., como na nota 65, p. 20, ao afirmar que "[i]st dies ein neues Naturrecht, welches Gott, Natur und Vernunft durch die Prinzipien geselchaftlicher Differenzierung ersetzt, also ein soziologisches Naturrecht? In der Sache unterläuft dieses Gerechtigkeitskonzept die Differenz von Positivismus und Naturrecht. Es erklärt beide für richtig und falsch zugleich. Mit dem Naturrecht teilt es den Impuls, Gerechtigkeit in einer von den Aussenwelt des Rechts stammenden Orientierung zu suchen. Doch mit dem Positivismus hat es gemein, dass die Gerechtigkeit nicht von externen Autoritäten, weder von Gott, noch von der Natur, noch von der natürlichen Vernunft vorgegeben ist, sondern nur innerhalb des Rechts erarbeitet warden kann".

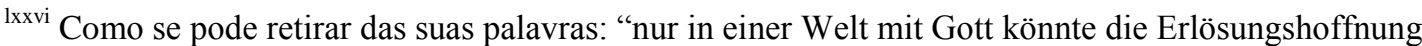
durch Gerechtigkeit bestehen. Wenn aber die Transzendenz ohne Gott gedacht wird, dann ist keine Erlösung in der Gerechtigkeit möglich", como na nota 65, p. 29. Ixxvii Idem. 
Ixxviii Curiosamente, TEUBNER afirma que existe um meta-código que se sobrepõe ao Direito e à Economia e que foi o motivo da mais recente crise económica, cfr., GUNTHER TEUBNER, "Ein Konstitutioneller Moment? Die Logik des hit the bottom", KLAUS GÜNTHER e STEFAN KADELBACH (coord.), Recht ohne Staat, 2010, p. 25.

${ }^{\text {Ixxix }}$ Ressalve-se que o autor não nega que "die Diskurse einander Gewalt antun", sendo que uma qualquer justiça discursiva não consegue dissipar a força auto-destrutiva da fragmentação discursiva. Ela surge apenas como uma justiça compensatória, tendo como função a minimização e compensação das injustiças discursivas, "Altera Pars Audiatur: Das Recht in der Kollision anderer Universalitätsansprüche", Archiv für Rechts- und Sozialphilosophie, n 65,1996, p. 218.

${ }^{1 x \times x}$ HANS Kelsen, O que é a Justiça, $2^{\mathrm{a}}$ Edição, tradução de Luís Carlos Borges, São Paulo, Martins Fortes, 1998, p. 215.

lxxxi Neste sentido, Luís PEDRo PEREIRA COUTINHO, como na nota 56, p. 537

lxxxii JoSÉ PINTO BRONZE, A Metodonomologia entre a semelhança e a diferença (Reflexão

Problematizante dos Pólos da Radical Matriz Analógica do Discurso Jurídico), Coimbra Editora, Coimbra, 1994

lxxxiii O Direito - Introdução e Teoria Geral, 13ª Edição, Coimbra, Almedina, 2005, p. 220.

${ }^{\text {Ixxxiv }}$ Cfr., como na nota 56, p. 539.

lxxxv JOÃO BAPTISTA MACHADO, Introdução ao Direito e ao Discurso Legitimador, $17^{\mathrm{a}}$ reimpressão, Coimbra, Almedina, 2008, pp. 289 e 290. 